\title{
DISCUSSÕES SOBRE O TRABALHO FEMININO NA POLÍCIA MILITAR DO ESTADO DE SÃO PAULO
}

\author{
Discussions about the Female work in the Military Police of the State of São \\ Paulo
}

\author{
Giulianna Bueno Denari'
}

\begin{abstract}
Resumo
0 presente artigo discute alguns aspectos do trabalho feminino na Polícia Militar do Estado de São Paulo (PMESP), apresentando sua história de inserção, as diversas funções femininas e conflitos que a presença dessas mulheres acarretaram. A pesquisa teve como metodologia qualitativa entrevistas semiestruturadas realizadas em diversas cidades do estado de São Paulo, com policiais mulheres e homens, de diversas patentes e funções. A análise mostra que o trabalho feminino na instituição surgiu como assistencialista visando às populações vulneráveis que chegavam todos os dias na capital no contexto das migrações da década de 1950. Diferentemente do contexto de inserção das mulheres no mercado de trabalho, as policiais femininos (categoria nativa) tiveram sua inserção restrita, porém com os mesmos direitos que os policiais homens da época. Com o passar dos anos e mudanças na própria instituição policial, o trabalho feminino foi se aproximando do trabalho ostensivo e se afastando do trabalho assistencialista, homogeneizando as formas de policiamento da PMESP. Podemos concluir que o trabalho da policial feminino não seguiu as tendências do trabalho feminino no Brasil como um todo no que diz respeito à jornada, pagamento e direitos, porém, podemos falar sobre processo de trabalho precário, quando entendemos as dificuldades e obstáculos que as mulheres enfrentaram e enfrentam dentro da instituição.
\end{abstract}

Palavras-chave: Trabalho Policial; Trabalho e gênero; Gênero; Polícia Militar do Estado de São Paulo.

\begin{abstract}
The present article discusses some aspects of the female work in the Military Police of the State of São Paulo (MPSSP), presenting its history of insertion, the diverse feminine functions and conflicts that the presence of these women brought. The research had as qualitative methodology semi-structured interviews carried out in several cities of the state of São Paulo, with female and male police officers of various patents and functions. The analysis shows that the female work in the institution emerged as an assistance worker targeting vulnerable populations who arrived every day in the capital in the context of the migrations of the 1950s. Unlike the context of insertion of women into the labor market, female police officers (native category) had their insertion restricted, but with the same rights as the police men of the time. With the passing of the years and changes in the police institution itself, the female work was approaching the ostensible work and moving away from the "assistencial work", homogenizing the forms of policing of the MPSSP. We can conclude that female police work did not follow the tendencies of women's work in Brazil as a whole with regard to the journey, payment and rights, but

\footnotetext{
${ }^{1}$ Doutoranda do Programa de Pós-Graduação em Sociologia da Universidade Federal de São Carlos
} (PPGS/UFSCAR). Email: giudenari@gmail.com
\end{abstract}


we can talk about precarious work process, when we understand the difficulties and obstacles that women faced and face within the institution.

Keywords: Police Work; Work and Gender; Gender; Military Police of the State of São Paulo.

\section{Introdução}

Buscamos neste artigo apresentar e discutir alguns aspectos do trabalho feminino na Polícia Militar do Estado de São Paulo (PMESP), apresentando sua história de inserção e as diversas funções femininas e conflitos que a presença dessas mulheres acarretara. Discutir a história e inserção das mulheres na Polícia Militar do Estado de São Paulo (PMESP) é importante para compreendermos os percursos dessas mulheres na instituição, mas principalmente, para analisarmos as mudanças no fazer policial ao longo dos anos. A história da inserção feminina foi abordada sob diversas perspectivas como, por exemplo, nos estudos de Moreira (2011), Souza (2014) e Denari (2015). Relataremos aqui brevemente o percurso histórico da inserção e principais mudanças acerca do trabalho das policiais femininos ${ }^{2}$.

Este texto é resultado da dissertação de mestrado defendida em 2016 pelo Programa de Pós-Graduação em Sociologia da UFSCar. O objetivo de tal pesquisa foi analisar o trabalho feminino na instituição a partir da junção das funções de policiamento, ocorrida na década de 1980. Para tal análise fizemos entrevistas qualitativas semiestruturadas com policiais femininos e masculinos, da capital e do interior, a partir de um contato com a técnica bola de neve, resultando em 20 entrevistas $^{3}$. Nosso alcance das entrevistas compreendeu policiais oficiais e praças $^{4}$, em função administrativa e

\footnotetext{
${ }^{2} \mathrm{O}$ termo será mantido em destaque dado ser uma fala nativa das e dos policiais entrevistadas/os. Conforme pudemos constatar durante a pesquisa, o pronome de tratamento dessas mulheres é mantido no masculino devido à chamada estética militar, que não flexiona as posições hierárquicas no gênero, como soldado e capitão, por exemplo. Também constatamos que muitas policiais preferiam ser chamadas pelo pronome masculino, indicando que quando assim tratadas, seria um indicativo de que o gênero não interferiria na ordem, ou seja, indicavam que tinham respeito e eram obedecidas quando tratadas pelo masculino.

${ }^{3}$ Sabemos que a técnica de bola de neve (obter contatos e indicações a partir de um entrevistado chave) tem limitações e vantagens. Destacamos como vantagem a possibilidade da realização de entrevistas qualitativas, uma vez que os contatos pessoais das entrevistadas e dos entrevistados nos possibilitaram a inserção no campo. Sabe-se que a instituição militar é muito fechada e rígida no contato com pesquisadores e pesquisadoras e esta técnica nos possibilitou superar algumas barreiras.

${ }^{4}$ Por oficiais são classificados as policiais e os policiais que fazem curso superior, ingressando na Academia de Polícia Militar do Barro Branco, por meio de vestibular comum aberto todos os anos com vagas limitadas. Os interessados podem ingressar com no máximo 25 anos e após o término do curso, ocuparão funções de comando.
} 
ostensiva, homens e mulheres, de acordo com as indicações obtidas pela técnica escolhida. Para este texto destacaremos as falas de policiais oficiais e praças que nos permitam relatar a história da inserção das mulheres, bem as mudanças em seus trabalhos ao longo dos quase 30 anos de alcance que nossas entrevistas tiveram.

Tendo sido admitidas visando um policiamento mais "humano", as policiais femininos foram encarregadas inicialmente do cuidado com mulheres, crianças, idosos, jovens em situação de delito e enfermos, na década de 1950. Seu território primordial de atuação eram as estações de trem e rodoviária, visando um cuidado extra com as migrantes e suas famílias que chegavam a capital do estado todos os dias. Resgatamos que na década de 1950 houve um movimento massivo de migração para a cidade de São Paulo, principalmente de populações vindas do Norte e Nordeste do Brasil, sob a promessa de melhores empregos e oportunidades, com a crescente industrialização na cidade:

(...) não resta dúvida que, no Brasil, o desenvolvimento econômico resultante da industrialização está associado a dois fenômenos complementares e concomitantes: o incremento das desigualdades regionais e a constituição de grandes metrópoles. Tanto um quanto outro fenômeno implicam na formação de grandes correntes de migração interna através das quais se processa uma maciça redistribuição de população (DURHAM, 1984, p. 20).

Essas policiais nunca realizavam as patrulhas desacompanhadas, sendo muitas vezes seguidas por policiais homens à paisana; eram vetadas de fazer um "controle combativo" e não realizavam prisões, chamando reforços (masculinos) quando fosse assim necessário. Moreira (2011) destaca o caráter materno que as primeiras 12 mulheres contratadas deveriam ter para com a população alvo de suas atuações. Na época, o policiamento paulistano ainda era dividido entre a Força Pública (policiamento ostensivo) e a Guarda Civil (policiamento investigativo). As mulheres foram inseridas dentro do corpo da Guarda Civil, criando assim o Corpo Feminino de Policiamento, reservando a atuação militar e ostensiva

A hierarquia dos oficiais, da mais baixa para a mais alta, se dá: $2^{\circ}$ Tenente, $1^{\circ}$ Tenente, Capitão, Major, TenenteCoronel e Coronel. Por praças são entendidos os policiais que fazem o curso técnico, ingressando por meio de concurso público a depender da necessidade e número de vagas disponíveis, variando de caso a caso; ao término do curso são alocados em funções ostensivas (policiamento na rua) por pelo menos dois anos antes de poderem pedir transferência para outras funções. A hierarquia dos praças, da mais baixa para a mais alta, se dá: Soldado, Cabo, $3^{\circ}$ Sargento, $2^{\circ}$ Sargento, $1^{\circ}$ Sargento e Sub-Tenente. 
aos policiais homens da Força Pública. Apesar da história remeter ao contexto da década de 1950, nas falas das policiais entrevistadas esse percurso foi destacado entre um misto de saudosismo e admiração.

\begin{abstract}
Uma mulher que era vítima ou que era agressora, parte de uma ocorrência. A mulher tem direito a ser revistada por outra mulher. Ela só pode ser revistada por um homem num lugar onde não exista condições de se chamar uma policial, mulher e na frente de outras duas mulheres. Então um homem pode te revistar. Então, nessa época em 55, era um pós-guerra ia tendo muita demanda, muita. Então foi criada a mulher policial, que era exatamente proteção e apoio pra crianças, mulheres e idosos. (Policial feminino, coronel, reformada).
\end{abstract}

Após a legislação aceitar a entrada de mulheres no corpo de policiamento, abriram-se vagas para o ingresso de mulheres que seriam comandadas pela coronel Hilda Macedo (esta que se tornou coronel assim que assumiu a função, a fim de poder exercer comando sob o pelotão feminino ${ }^{5}$ ). Depois de alguns meses de treinamento, em dezembro de 1955, as 12 aspirantes a policiais ficaram conhecidas como as "13 mais corajosas de 1955", juntamente com a coronel Hilda Macedo.

Como principal e indispensável função, deveriam ter uma postura disciplinada, seguindo os preceitos militares de altivez e seriedade, mas sem serem ríspidas, uma vez não ser atributo da representação do feminino valer-se de ações violentas. Sendo as características socialmente atribuídas, femininas e masculinas, tratadas de forma binária, ou seja, em oposição uma à outra, entendemos então que a postura masculina não seguia desta forma. Alguns relatos afirmam que na época, os policiais masculinos se envolviam mais em brigas, conflitos violentos e corrupção, mas sempre tratados como casos antigos, no passado, pelos relatos das entrevistadas e entrevistados da pesquisa.

Soares e Musumeci (2005) analisam que a entrada da mulher na instituição policial militarizada era uma tentativa de melhoria da imagem da PMESP diante da população, porém, não entendem essa inserção como uma medida efetiva de mudança, mas uma "mudança estética". Ao direcionar o policiamento feminino nos patrulhamentos com maior visibilidade - estações de trem, rodoviária e o cuidado com o trânsito - davam destaque a uma

\footnotetext{
5 Apesar de serem do policiamento civil, as mulheres seguiam os preceitos militares, assim como os policiais da Força Pública, na época. Desta forma, um pelotão (grupo de 30 policiais) só poderia ser comandado por uma Coronel formada, o que permitiu que a idealizadora do Corpo Feminino de Policiamento fosse promovida a Coronel imediatamente.
} 
atuação "maternal" da polícia para com os mais vulneráveis, ou seja, enfatizavam a atuação feminina recém incorporada e apontavam como se fosse uma mudança geral da instituição policial, não apenas uma atuação do corpo feminino. Porém, como apontam as autoras, continuava cabendo aos companheiros de profissão homens lidar com o policiamento ostensivo, mais violento, no entanto, sem chamarem tanta atenção para sua atuação, diminuindo as possiveis criticas a um policiamento mais violento.

Podemos entender que houve um direcionamento do policiamento feminino para os cuidados com a população, mais uma atuação preventiva do que o combate ostensivo a delitos, por exemplo. Para compreender esse trabalho designado às policiais femininos, buscamos na literatura sobre trabalho e gênero categorias que nos ajudassem a desnaturalizar essas funções. De acordo com Molinier (2012), o trabalho que ela chama de care tem características muito especificas, que podem ser associadas ao trabalho exercido pelas policiais no momento de sua inserção na carreira policial. A inserção que se deu em 1955 permaneceu até os anos 2000 com as funções separadas, ou seja, homens e mulheres atuavam em batalhões separados e as mulheres não podiam atuar nos mesmos setores e serviços que os homens. A distinção e divisão entre as formas de trabalho exercidas eram então definidas por lei, tendo mudando apenas recentemente. Esse cuidado (care) estudado em outras funções exercidas por mulheres historicamente, funciona aqui também como categoria analítica e é definido pela autora:

(...) care designa o trabalho no sentido do serviço bem feito, na medida em que este nunca se resuma a uma habilidade técnica, ou seja, care sempre supõe esse "suplemento" que torna a relação de dependência suportável e o serviço realmente eficaz (...). Sua autonomia é uma ficção sustentada pelo trabalho de apoio e de antecipação que lhes é prestado. Esta é uma das complexidades enfrentadas para se tentar levar em consideração o care, na confluência entre relações sociais de sexo, de classe e de raça, onde os homens, as classes privilegiadas, os brancos, dominam/ exploram as pessoas que realizam o trabalho do care a seu serviço, enquanto, na prática, eles dependem deste trabalho: seu conforto, assim como sua eficiência, dependem da qualidade do trabalho de care. (MOLINIER, 2012, p. 33).

O termo care, de acordo com Molinier, "é por definição, um gesto ou uma forma de agir (ou de não agir) ajustados ou afinados às necessidades do destinatário, que pode ser, inclusive, marcados pela distância ou o desapego. 
É essa arte do ajuste a situações sempre particulares que o caracteriza e que assina a invisibilidade ou a descrição" (idem, p. 32). As traduções mais comuns para o termo são "cuidado", "solicitude" e "atenção ao outro", abrangendo assim, as mais diversas funções. Adotamos o termo "cuidado" como tradução, por nos parecer mais apropriado de acordo com o que aparece na legislação de inserção das mulheres na PMESP como função das policiais e pelo que também foi apresentado nas falas das policiais entrevistadas.

Essa restrição do trabalho das policiais femininos ou fox 6 é relatada tanto na principal pesquisa realizada sobre a inserção da mulher na PMESP7 quanto nas falas das policiais entrevistadas para a pesquisa. Mesmo havendo uma distância de mais de 50 anos desde a primeira mulher policial da instituição, as entrevistadas ainda relatam tais restrições, na atuação, no fardamento e os preconceitos da época, o que mostra que a história dessas mulheres ainda é referência, de alguma forma ainda hoje.

A partir de então, sucederam-se mais decretos em relação à efetivação do quadro de mulheres na polícia militar, determinando funções, armamento e vestimentas adequadas. Todo o fardamento policial é regido por códigos e manuais para que os policiais se mantenham no padrão. No início do trabalho feminino de polícia, o fardamento era muito diferente do que se vê hoje:

Quando eu entrei meu uniforme era esse: uma saia calça, meia fina, sapatinho e a bolsinha. Porque a policial, no começo, a função dela era mais assim, uma função de assistente social. Eu via lá em São Paulo, as policiais, elas trabalhavam lá no Tietê, apoio a famílias, a pessoas indigentes que iam lá, elas orientavam, encaminhavam, crianças perdidas... era mais um trabalho social. Tanto é que quando eu cheguei aqui (Interior), nossa a gente era que nem bibelô de festa, a gente falava. A gente trabalhava no teatro municipal, em bailes do dia das mães... era totalmente diferente do que a gente faz hoje. (Policial feminino, $1^{\circ}$ sargento, administrativo).

\footnotetext{
6 Outra nominação dada às policiais. Ao perguntar se há alguma relação com a tradução direta do inglês para "raposa", foi negado imediatamente. A justificativa dada foi a nomeação pelo chamado Código Q, adotado para facilitar a comunicação entre os policiais. As entrevistadas e entrevistados para a pesquisa informaram apenas que esse código usa as letras do alfabeto para simplificar a comunicação entre os policiais e que a letra F, designando feminino, é traduzido por Fox nesse código, assim como a letra M, se masculino, seria Mike.

7 MOREIRA, R. Sobre Mulheres e Polícias: A construção do policiamento feminino em São Paulo (19551964). 2011.
} 
No início dos anos 2000, ficou instituído em São Paulo que as funções dos efetivos masculino e feminino não seriam mais separadas, possibilitando uma maior abrangência de atuação das mulheres nas funções de policial militar. Em 2001, o então governador do estado, Geraldo Alckmin, criou o Dia do Policial Militar Feminino, a ser comemorado em maio. Essas são algumas das primeiras mudanças em relação ao efetivo feminino. Alguns anos mais tarde, os quadros do efetivo policial foram unificados, possibilitando assim, que toda e qualquer função na PMESP possa ser exercida legalmente por mulheres. No ano de 2015 eram três coronéis na ativa, ocupando diferentes funções de comando na instituição, sendo que são apenas pouco mais de 50 policiais que ocupam o posto de coronel, só ascendendo ao posto um novo coronel, quando algum entra para a reserva.

\section{Sobre o trabalho policial e as diferenças}

No Brasil foi a partir da década de 1990 que houve a expansão da inserção da mulher no mercado de trabalho. Na mesma época começa o processo de precarização dessas relações, após a reestruturação produtiva e principalmente as crises econômicas que seguiram nesta época. Se a precarização é fruto da inserção da mulher nesse mercado já visando essa realidade ou se houve a precarização devido ao aumento dessas mulheres nos diversos setores, não há como afirmar categoricamente. A questão é que esses processos se deram de forma concomitante e afetaram diversos setores e ramos do mercado de trabalho desde o início dos anos 1990 no país. As

principais características do trabalho precário são entendidas sobre as relações de trabalho, ou seja, não registro formal, falta ou poucos direitos trabalhistas, a forma de contratação temporária, ou nenhum contrato.

No que diz respeito a determinadas características de um trabalho precário, as policiais femininos não se enquadram: são contratos estatutários, com igualdade salarial, alcance de cargos superiores que demandam concurso e/ou tempo de serviço e licença maternidade, por exemplo. Porém, podemos dizer sobre a precarização das relações, dos processos de trabalho, quando pensamos no sistema de plantões, escalas e o tipo de trabalho exercido pelos policiais, porte de armas, ameaça de 
confrontos, entre outros. As funções exercidas, os processos de trabalho são entendidos aqui como precários. Como apontam Santos, Fachinetto e Teixeira (2012), em pesquisa sobre gênero da Segurança Pública do Rio Grande do Sul, as mulheres ganham as mesmas faixas salariais que os homens nos mesmos cargos, porém, podemos questionar o quanto elas conseguem chegar aos mesmos cargos que seus colegas, quando pensamos em posições que demandam indicação dos superiores e acordos políticos, por exemplo.

Apesar de todas as vantagens trabalhistas, as mulheres que normalmente cuidam de suas casas, quando em plantão, não tem direito a creches noturnas ou licença para cuidar de seus filhos quando doentes. Como abordam Brasil e Fachinetto (2016) em suas pesquisas nacionais sobre mulheres policiais (civil e militar) realizadas durante os anos de 2012 a 2015 englobando policiais das mais diversas funções e cargos dentro das instituições, a precariedade dos processos de trabalho existe apesar dessas garantias institucionais. Conforme apontam os resultados da pesquisa acima mencionada, além de muitas vezes não possuírem equipamentos adequados, como coletes a prova de balas no tamanho correto ou no formato do corpo feminino, a estrutura dos batalhões e delegacias não possuírem banheiros e alojamentos específicos para as mulheres, há também uma precariedade nas relações estabelecidas entre homens e mulheres e entre as próprias mulheres. Os relatos trazidos no artigo mostram que muitas vezes a estrutura militar rígida impõem que as oficiais possam ocupar os espaços, já ruins, de banheiro e alojamento, reservando às praças que usem os espaços ao público para trocarem de roupas e vestirem a farda, por exemplo.

Essas garantias oficiais de ascensão e promoção na carreira policial são relativizadas quando trazemos as falas das policiais femininos da nossa pesquisa. As entrevistadas argumentaram que apesar de oficialmente poderem concorrer aos mesmos cargos que seus colegas homens de profissão, isso não significa que não existam barreiras para ascensão aos cargos e funções mais altas e de prestígio na instituição, como por exemplo chefe da casa militar, ou comandante geral da PMESP. Conforme argumenta Bonelli (2011), o "glass ceiling" ou "teto de vidro" atua como barreiras 
efetivas, porém não legalizadas, para a ascensão de mulheres em suas carreiras. No que diz respeito às funções, patentes e postos que podem ser assumidos apenas de acordo com o tempo de serviço e devido a concursos, as mulheres conseguem alcançar os mesmos postos. Porém, quando se trata de avaliações de seu trabalho ou negociações politicas, haveria o então chamado "teto de vidro", que Bonelli pesquisadora resgata autores como Junqueira e Thornton para abordar o assunto nas carreiras jurídicas. Esse "teto de vidro" seria então, segundo Bonelli (2011):

(...) barreira invisivel que dá a ilusão de igualdade de oportunidades na carreira, mas bloqueia o acesso às posições elevadas da hierarquia profissional, mantendo as advogadas nas atividades menos valorizadas, que não preparam para posições de prestígio e poder, e têm pouco contato com cliente (BONELLI, 2011, p. 277).

O argumento dado pelas policiais e pelos policiais entrevistados é que tais barreiras não existem, uma vez que a carreira militar é seguida por tempo de serviço e cursos/concursos que os policiais se inscrevem ao longo dos anos. A fala de que as mulheres são mais esforçadas e almejam postos mais altos, estudando e se esforçando mais que os homens para isso é corriqueira. Mas se esse esforço e melhor rendimento em concursos é uma realidade do trabalho feminino na polícia, o fato delas não terem tanto espaço nas posições de comando pode indicar que esse tipo de trabalho não é o primeiro a ser levado em consideração quando policiais são promovidas e colocadas no comando.

No caso da PMESP, há uma obrigatoriedade de nos 2 primeiros anos após a formatura no curso para soldados, que todos exerçam o que eles chamam de funções "de rua", ou seja, exercer o policiamento a pé, cotidiano, patrulhando locais públicos. Uma policial engravidar nesse período atrasa sua ascensão na carreira, porque deve ficar afastada de suas funções: a barreira não é mais explícita, mas ela ainda existe.

De acordo com Perticarrari (2007), a realidade da mulher no mercado de trabalho é semelhante após o aumento de sua participação neste: a mulher se adaptaria melhor às exigências e demandas do setor empregatício no que diz respeito à escolaridade, especialização e disponibilidade. Segundo o autor, a incorporação do trabalho feminino de acordo com as funções já socialmente atribuídas às mulheres reflete a segregação e limitação impostos 
a essas mulheres. "As relações entre os sexos ainda são predominantemente assimétricas e hierárquicas, assim como são desiguais as posições ocupadas pelos indivíduos dos dois sexos sejam na esfera da produção ou das relações familiares" (PERTICARRARI, 2007, p. 40).

A rotina de um policial militar é determinada de acordo com escalas de serviços: o policial pode solicitar um horário de serviço, mas cabe ao comandante determinar quais policiais atuaram em quais horários. Há nas falas das entrevistadas e dos entrevistados, a preocupação com o cuidado familiar devido a essas escalas, pois: "quem vai cuidar dos filhos? Se você não tem rotina fixa, quem vai cuidar dos seus filhos?” (Soldado, masculino).

No que diz respeito ao cuidado com a família e a permanência no trabalho, a realidade brasileira estaria relacionada ao modelo da delegação, segundo as autoras Hirata e Kergoat (2008). Elas apontam dados sobre o número de mulheres dentro do serviço doméstico fora de suas próprias casas, o que mostra um grande número de mulheres que atuam em serviços particulares, uma vez que podem delegar a outras as tarefas domésticas.

Vê-se que as categorias históricas se misturam no contexto histórico e geográfico específicos: não dá para argumentar sobre gênero sem levar em consideração as categoriais de classe e raça ${ }^{8}$. Porque quando mulheres conseguem delegar a outras o serviço doméstico e o cuidado com os filhos, normalmente são mulheres de classe alta e brancas delegando às mulheres negras e pobres. Porém, ainda são mulheres que ocupam esses cargos que remetem ao cuidado do lar, para que outras mulheres passem a buscar trabalhos no âmbito público. Hirata e Kergoat (2008, 2012) mostram também a relevância das normas sociais para determinar o contexto de inserção e ação dessas mulheres e no Brasil, a necessidade de poder "se virar" aparece como predominante, principalmente nas camadas sociais mais baixas, já que fazem o papel de cuidadoras do lar de outras mulheres para que estas possam trabalhar "fora de casa", e "se viram" para dar conta de cuidar dos dois lares.

E também tem a situação do policial ter que se adaptar o horário, porque não dá pra gente fazer só o horário que a gente quer, tem que

\footnotetext{
8 Sabemos da importância de estudos sobre interseccionalidades, porém para este texto optamos por não aprofundar na discussão. Como referência, apontamos: Piscitelli (2008).
} 
fazer o horário que a instituição precisa. Então a gente tem que se adequar a vida pessoal ao horário de trabalho. Porque vamos supor, se eu trabalhar numa fábrica, eu não tenho que adequar a minha vida ao horário da fábrica? Lá também, eu tenho que adequar a minha vida ao horário da polícia. Dentro do que dá pra acertar, se acerta. O que não dá pra acertar a pessoa tem que se acertar, porque ela tem que cumprir horário. É um emprego. (Policial feminino, Subtenente, aposentada).

A valorização da força como a principal característica de um policial militar, ou ao menos, saber usar de sua força física, para proteger a população e a si mesmo, mostra qual a importância do biológico, do físico em si, para diferenciar e demarcar a separação das atuações na instituição. Essa construção social que supervaloriza um tipo de potência física como o bom e ideal faz com que as relações de poder entre os policiais sejam determinadas por capacidades que medem apenas uma das características da atuação policial, colocando em segundo plano potências que também são necessárias para o trabalho policial, mas que no momento de justificar desigualdades entre homens e mulheres, não aparecem. Entende-se que, mesmo que haja essa busca por amenizar a visão truculenta da instituição policial, a imagem do policial forte, potencialmente repressivo e heroico é ainda a valorizada e desejável por parte da população e da instituição.

Sobre a naturalização das funções sociais de homens e mulheres no cotidiano das falas das/os interlocutores da pesquisa, mas não apenas nessas esferas: a atribuição de papéis e categorias ao feminino e ao masculino é algo comum, cotidiano, inclusive (e talvez principalmente) na ciência e na polícia não se mostrou diferente na maioria dos casos.

Talvez o homem, ele tenha mais essa coisa do poder. Porque o homem, eu acho que ele vive muito pra carreira né? A mulher, a gente tem filhos, tem família, tem marido, então a gente tem aquela pressão de ser dona de casa, de cuidar das crianças, de dar lição, da mãe, do sogro doente, né? Então a gente é muito cuidadora, a mulher tem isso. Então a gente procura, a gente se divide né? Eu tenho que ter várias máscaras, vários papéis. Aqui eu sou coronel. Lá em casa eu sou mãe, eu sou esposa... tem que ser amorosa (...). (Policial feminino, coronel, administrativo).

Muitas falas, principalmente das policiais mais antigas de profissão, mostram o quanto no início, a mulher era colocada em uma posição de privilégios dentro da atuação policial: apesar de não exercerem as mesmas funções que os homens, eram vistas como mulheres de extrema coragem 
para lidarem com a população nas ruas de uma cidade tão grande quanto São Paulo. Eram os ideais de honra, luta e justiça, presentes no discurso militarizado, adaptados de alguma forma à atuação das policiais femininos colocados como seres dignos de uma importância exacerbada.

As falas dos policiais entrevistados trazem também os discursos de superação e o alto número de mulheres no oficialato militar, exercendo as mais diversas funções. Quando as policiais falam sobre preconceitos e dificuldades, trazem situações vividas por outros, muitas vezes vividas há anos e que nos tempos atuais, essas situações não aconteceriam. Admitem algumas vezes haver preconceito, principalmente dos subordinados em receber ordens femininas, mas que é um preconceito velado, principalmente devido ao respeito à hierarquia rígida da instituição. O discurso militarizado, ou seja, a importância da hierarquia e estética militar para os policiais são abordados como algo bom, uma vez que não daria oportunidades para que preconceitos e problemas pessoais interfiram no trabalho cotidiano dos policiais. Como a hierarquia é rígida, um subordinado não obedecer a ordens significa crime militar, passivel de punição. Da mesma forma, uma ordem é sempre uma ordem, independentemente de quem a dá, o que descaracteriza, na visão das policiais, possiveis abusos por diferenças de gênero.

Preconceito? Tem ainda, internamente...eu acho que tem. Eu acho que tem ainda. Porque o pessoal ainda olha assim...receber ordem de uma mulher. Mas é uma coisa um pouco mais velada. É uma coisa um pouco mais velada. A gente percebe, assim, que tem muitos homens que não gostam de receber ordem de mulher. Ainda mais no meio militar, entendeu? Mas são obrigados a receber ordem, entendeu? Mas são obrigados a receber ordem, entendeu? Então eles não podem se opor, até pelo próprio regime militar. Mas a gente percebe um descontentamento. Então, de uma forma velada... mas eu acredito que em todas as áreas ainda exista preconceito com o trabalho com a mulher. (Policial feminino, subtenente, aposentada).

Argumentam também que o preconceito em relação ao trabalho feminino não seria maior ou menor no que é encontrado em outras profissões, trabalhos, setores e esferas sociais, por isso, conseguem identificar situações de preconceito e desvalorização de seu trabalho na atuação cotidiana, principalmente em relação à população. Falando sobre o preconceito da população:

(...) eu acho que acontece, até. Mas faz parte daquela minoria que tem preconceito. Então assim como a gente tem internamente, tem 
externamente. Às vezes você vai falar, passar uma orientação...que nem, já aconteceu comigo: eu trabalhando com um outro policial, eu sou graduada e ele não, e eu vou passar uma orientação e a pessoa prefere ouvir da boca dele. Porque parece que o homem falando tem mais segurança, é mais certo ou inspira mais confiabilidade, não sei. (Policial feminino, subtenente, aposentada).

A estética militar coloca como primordial importância o respeito à hierarquia e principalmente, a forma de ascensão na carreira. Desta forma, enquanto homens e mulheres concorriam em quadros separados e por ter menos mulheres que homens, elas ascendiam mais rapidamente que eles na hierarquia, pois elas tinham que ocupar o mesmo número de cargos que existiam para o QOPM. Mas como os quadros de ascensão eram separados, as mulheres nunca poderiam chegar a concorrer aos mesmos cargos e funções que os homens, minimizando assim os conflitos, pois eles pouco conviviam durante suas atuações, sendo poucos os grupos "Romeu e Julieta"9, por exemplo.

Com a unificação das funções e a consequente extinção dos Batalhões de Policiamento Femininos, as mulheres continuaram a disputar as patentes a partir do tempo de policiamento delas, porém dentro de um quadro de funções agora unificado. Desta forma, mulheres com menos tempo de exercício da profissão acabaram por alcançar patentes superiores antes que homens que se formaram antes que elas. Isso é o que eles chamam de "dar balão"10 e é a partir disso que surgem os maiores conflitos, possibilitando que os conflitos de gênero fiquem "velados", ou seja, sejam justificados pelos conflitos de hierarquia.

Eu não tenho nada assim pra reclamar, mas quando uniu o quadro, teve muita, na graduação assim de sargentos, né? Que elas, passaram na frente. (risos) Eu sou terceiro sargento, vai...ai...não, eu sou segundo sargento, ai a outro é terceiro. Eu já sou segundo

\footnotetext{
9 O chamado policiamento "Romeu e Julieta" refere-se ao policiamento exercido por homens e mulheres antes da unificação dos quadros. Como explica uma das policiais entrevistadas: "Tinha um policiamento na área central de São Paulo que foi chamado de Romeu e Julieta. Que era uma policial feminina e um policial do canil e a gente fazia patrulhas em toda área central de São Paulo, o centro velho, né? E tudo, visando prevenção, visando orientação, visando acompanhamento, essas coisas todas". (Policial feminino, coronel, reformada).

10 Essa expressão foi usada pelos policiais homens durante as entrevistas para justificar alguns conflitos em suas falas sobre a convivência com mulheres nos locais de trabalho. "Dar balão" significa que, quando houve a unificação dos quadros do efetivo feminino e masculino, a contagem de tempo e o número de policiais em cada patente tinham contagens iguais, porém com um número de efetivo diferente. Os policiais argumentam que quando houve a unificação, algumas mulheres conseguiram subir de patente mais rapidamente do que eles, ou então subiram de patente automaticamente, para igualar os quadros, o que segundo os entrevistados, prejudicou policiais homens e que tinham os mesmos tempos e requisitos para subir de patente.
} 
sargento há dois anos e você é terceiro recruta, assim antigo. Ai houve a unificação, do nada, você foi segundo sargento e mais antigo que eu. (risos) Você entendeu? Quer dizer, quando for a primeiro sargento, você vai ser primeiro que eu, que sou mais antigo de segundo, fiz escola primeiro. Por que aconteceu? (risos) Eu acho que foi uma mulher que mandou nisso ai (risos), eu não sei como é que foi não. Mas ouvi muito pessoal reclamando a respeito disso. (Policial masculino, $1^{\circ}$ sargento, administrativo).

Não, não tem. Não tem. É, por exemplo, se ele vai trabalhar... é... dificilmente muda. O que o comandante faz é... ele muda o policial quando realmente tem a necessidade, entendeu?! Se é uma coisa que está prejudicando realmente o serviço, ele está vendo que não vai dar certo, que não vai surtir efeito, aí ele muda. Agora este tipo de preconceito, ele é um preconceito velado. O policial não chega e fala: "ai, eu não quero trabalhar com ela, porque ela é mulher". Não... entendeu?! Ele dá umas disfarçadas, faz vista grossa para alguma coisa, deixa de fazer alguma coisa... você tem que chamar atenção, você tem que por... sabe?! Mas ele não fala claramente. Então não é uma coisa que chega no comando para ser resolvido. É uma coisa que fica ali nos bastidores. "Eu não gosto, mas eu tenho que suportar por conta do regime militar". Pela hierarquia, entendeu? (Policial feminino, subtenente, aposentada).

A fala sobre o preconceito sofrido por essas mulheres, principalmente no que diz respeito ao preconceito sofrido dentro do ambiente de trabalho por seus pares aparece sempre como "preconceito velado", conforme já abordado. O relato sobre preconceito e assédio apareceu de um policial masculino, que narrou sobre policiais que sofreram e exerceram assédio no trabalho.

Tem muito (assédio). Então é assim, geralmente o comandante né? Algum interesse. Mas existe sim. Existe esse assédio. Mas assim, eu acho que se a mulher se der ao respeito, opa na primeira entrada, ou na primeira engraçada que o cara der ela falar: ó chefe, é o seguinte, eu sou casada, vamos trabalhar porque se não eu vou pedir pra sair daqui e acabou. Põe a pessoa no lugar dele. Assim como existe de mulher pra homem. Existe. A cantada da mulher, só que o homem, ele leve de boa, se ele não quiser a mulher, ele já desencana, já sai... a mulher não vai ficar ali. Mas o homem não, o homem já é mais atirado, ele tenta uma, duas, três, quatro...ele vai tentando. Agora se puser o cara no lugar dele, ele não vai tentar mais. (Policial masculino, $1^{\circ}$ sargento, administrativo).

É interessante apontar o quanto esse discurso apareceu de forma diferenciada nos relatos das policiais entrevistadas, ou seja, sempre apontados como situações veladas, pouco corriqueiras e principalmente, nunca sofridas pelas mesmas ou colegas próximas. Apenas uma das policias entrevistadas relatou sobre uma situação de preconceito, quando ao subir de patente, para tenente-coronel, seus colegas demoraram a aceitar e obedecer a suas ordens, agindo de forma mais lenta, ou questionando suas decisões. 
Segundo ainda seu relato, mesmo protegida pelo militarismo e tendo a possibilidade de notificar, advertir e mesmo punir seus subordinados, a situação era compactuada pelo comandante, uma vez que sob a justificativa dela ter "dado balão" em seu posto, ela não deveria estar naquela posição. A alternativa adotada para lidar com essa questão foi resolvida quando esta conseguiu entender que esse preconceito existia e então, passou a adotar uma postura mais rígida, masculinizada e baseada nas ordens oficiais do Comando Geral. Ela relatou que com o tempo, após a mudança de seu comandante direto, a situação melhorou, uma vez que havia conseguido conquistar o respeito de seus subordinados e tinha a compreensão e apoio de seu novo comandante.

Algumas policiais disseram que entre aqueles que se encontram na mesma posição hierárquica acabam por não demonstrar problemas com suas colegas policiais. Mas esse discurso vem acompanhado pela fala de que para isso as mulheres por principio se esforçam mais, mostram mais trabalho e buscam se destacar mais em suas funções: desta forma, se mostrariam iguais aos homens e de alguma forma, estariam "conquistando seus espaços" como policiais. Quando não, a hierarquia militar é acionada para justificar formas de agir, sendo ao mesmo tempo uma forma de proteção para essas mulheres, mas também manutenção de preconceitos, como as pesquisas de Pasinato (2013) e FBSP (2015).

Quando a fala sobre preconceito aparece nos relatos das policiais entrevistadas são feitas referências aos preconceitos e dificuldades enfrentadas quando lidavam com a população.

Aqui teve muito, assim, desacato. Os homens no começo não botavam fé na gente. A população. Você ia autuar o indivíduo lá que estava errado e eles achavam que porque a gente era mulher que a gente não tinha autoridade de fazer aquilo. Então a gente teve que mostrar, no começo foi dificil, que a gente estava ali como policial, apesar de estar de sainha e sapatinho, a gente era policial. Depois de uns par de desacato pessoal falou opa! É polícia também. (...) (Policial feminino, $1^{\circ}$ sargento, administrativo).

Apesar desse reconhecimento, esses relatos apareceram também como forma de mostrar que essa realidade mudou, uma vez que as policiais não enfrentariam mais essas situações no policiamento atual. Como a mesma policial relatou, quando a população começou a reconhecê-las como 
policiais, foi no momento que passaram a fazer o mesmo tipo de policiamento que os homens faziam: patrulhamento, "pegar ladrão", revista em eventos e principalmente, quando o fardamento se tornou igual para ambos. O trabalho delas passou a ser respeitado e reconhecido quando abandonado o caráter exclusivamente assistencialista, elas passaram a seguir com o modelo militarizado e combativo.

As falas dos policiais entrevistados para a pesquisa possuem uma preocupação em mostrar que o preconceito é cada vez menos visível, menos constante. O que não significa que seja menos efetivo e real em suas consequências. Mas que ele existe em algumas camadas, em algumas esferas de sua vida. No entanto, esse preconceito velado, escondido pode ser muito mais nocivo que o exposto e confirmado: pode criar barreiras e situações constrangedoras que se naturalizam.

Desta forma, a violência acarretada pela dominação não é necessariamente física (mas pode ser); ela pode estar vinculada a elementos da vida cotidiana que os fazem quase imperceptiveis, e assim, são naturalizados, causando danos reais, concretos. Porém, tratar sobre preconceitos e problemáticas de desrespeito e desacatos não se mostrou um assunto do qual as policiais preferissem tratar. Os motivos podem ser diversos: desconforto produzido pelas lembranças, o desconhecimento ou não reconhecimento das situações de violência, por exemplo. Porém, algumas das policiais entrevistadas relataram o quanto se esforçam e se esforçaram para viver e conviver profissionalmente apesar de tudo isso, o quanto para elas, existem formas de resistências que concretamente, as ajudam a seguir no cotidiano de seus trabalhos e ascender em suas carreiras.

A mesma policial indicou que há uma necessidade, entre os pares de mesma patente, de uma maior provação por parte da mulher. Sendo a força física supervalorizada em alguns setores da instituição, ela não é colocada como opção, mas como necessidade. Por isso, a fala de Beauvoir, apesar de datada e localizada, surge com sentido atual: se a mulher consegue "se provar" e atuar igualmente nas diversas profissões e trabalhos cotidianos, como ainda justificar preconceitos e a dominação? Segundo Beauvoir: 
É no momento em que a mulher se acha mais emancipada, praticamente, que se proclama a inferioridade de seu sexo, o que constitui um notável exemplo do processo de justificação masculina de que falei: como não limitam mais seus direitos como filha, esposa, irmã, é como sexo que lhe recusam a igualdade com o homem, pretextando, para dominá-la, "a imbecilidade, a fragilidade do sexo" (BEAUVOIR, 1970, p. 116).

Podemos ver o quanto essa realidade é presente nas vidas dessas mulheres em termos nacionais ao analisarmos os dados obtidos nas pesquisas de Brasil e Fachinetto (2016). As autoras argumentam que para além de processos precários de condições de trabalho físicos, como falta de alojamento e de equipamentos de segurança adequados, as disputas impostas e vivenciadas por essas mulheres para que consigam algum destaque em suas funções seria também um fator de precariedade no exercício de suas funções. As falas sobre o esforço excessivo e a competição exacerbada entre as próprias mulheres ou seus colegas homens mostram o quanto o fazer policial vai além das práticas cotidianas de segurança pública e como o trabalho policial é permeado de disputas, buscas por reconhecimento e condições mínimas para realização do trabalho.

No entanto, as mulheres começam a expandir suas áreas de atuação e crescer em número nos concursos e cursos de formação na PMESP ${ }^{11}$. A busca por mostrar a pesquisadora o quanto elas conseguem existir e agir como policiais, apesar de quaisquer impedimentos, pode ser um indício desse crescimento relatado em campo: há uma tentativa identificada em alguns setores de desmistificar a mulher como vítima que não age ou cria estratégias profissionais para lidar no cotidiano de suas funções. As policiais entrevistadas buscavam argumentar que essas barreiras ou impedimentos não eram impeditivos reais para sua ascensão na carreira, mas funcionavam como motivadores para que se esforçassem mais e buscassem atuar de forma mais proativa, nos moldes e a partir dos critérios que seus colegas e superiores homens colocavam. Tais falas aparecem em vários contextos

11 Tal informação é relatada em campo por oficiais (femininos e masculinos) durante a pesquisa. Porém, os dados quantitativos que comprovem ou reprovem tal informação não foram fornecidos pela instituição para esta pesquisa. Na pesquisa Mulheres nas instituições policiais, divulgada pelo Fórum Brasileiro de Segurança Pública em 2015, há dados sobre a inserção de mulheres nas instituições policiais em todo o Brasil, porém, os dados não são conclusivos para esta pesquisa, uma vez que apesar de trazerem os dados sobre cada polícia em separado (PM, PC, PF, PRF, CB, PC/P, e GM), não há dados particularizados sobre cada estado brasileiro, o que impede a sua utilização. 
diferentes, como podemos observar a partir das pesquisas de Soares e Musumeci (2005), Santos, Fachinetto e Teixeira, (2012), Souza, (2014), Brasil e Fachinetto (2016), que estudaram diferentes instituições de segurança pública em diferentes estados brasileiros. Fazemos ressalvas que apesar de estruturas de funcionamento muito semelhantes, os contextos de formação e o processo de inserção da mulher na PMESP se diferencia por ser o mais antigo, ter acontecido ainda antes do processo de recrudescimento da ditadura no Brasil (caso dos outros estados no Brasil que passaram a incluir mulheres em seus efetivos a partir da década de 1970) e por ter extinguido a cota de inserção da mulher recentemente, possibilitando a livre concorrência nos processos de recrutamento de homens e mulheres.

\section{Considerações finais}

A história das mulheres na PMESP é contada oficialmente de forma quase sem conflitos, sem diferenças de vivências, sem disparidades de construção da carreira entre as mulheres e seus colegas homens. São colocadas enquanto um grupo atuante que foi de alguma forma sobrevivendo dentro da instituição e conseguindo postos, mesmo que de forma limitada e restrita. As falas das entrevistadas buscam ressaltar a importância aprovação cotidiana de seu trabalho e suas atuações positivadas em relação à construção de suas carreiras. No entanto, pudemos observar a partir de algumas falas de seus colegas ou mesmo quando se referiam a outras policiais femininos, que a permanência dessas mulheres na instituição não se deu sem conflitos e sem resistências. O que nos mostrou ser importante para a compreensão desses casos é a estrutura militar rígida, que permite tanto às mulheres buscá-la quando vivenciam momentos de desacato, quanto não reconhecer situações de preconceito e desigualdades de gênero na instituição, o que acaba embaçando as relações de gênero na instituição.

A divisão sexual do trabalho não existe formalmente nas falas dos entrevistados: a livre concorrência, o mérito e, principalmente, o perfil do policial são as principais características apontadas para ascensão na carreira e ocupar os postos de comando, estes que possuem o maior prestígio na instituição. Porém, trabalhos como os de Soares e Musumeci 
(2005) e da pesquisa coordenada por Pasinato (2013) apontam que há uma permanência em alocar as mulheres em funções de baixo prestígio na carreira. Tais funções são associadas, de acordo com tais pesquisas, ao feminino e representam tudo que há de "não-viril" na instituição. Conseguimos acessar pelas falas das entrevistas que recentemente há mulheres ocupando ao menos algum cargo em todos os setores da PMESP, mas isso após a junção dos quadros do efetivo policial. O único lugar apontado que não há mulheres no policiamento ostensivo foi a ROTA (Rondas Ostensivas Tobias de Aguiar), oficialmente chamado de $1^{\circ}$ Batalhão de Choque, apontada como o policiamento mais violento e que precisaria de dispêndio de mais força física e dedicação exclusiva da polícia paulistana. Não obtivemos dados oficiais sobre isso, tendo as entrevistadas indicado apenas que a secretária do batalhão seria uma policial feminino.

O perfil necessário para determinadas funções, como ronda escolar, policiamento comunitário e projetos de educação nas escolas, descritos pelas entrevistadas nessa pesquisa apontam características atribuídas socialmente ao feminino: paciência, carinho, afeto, sentimentos, "jeitinho". E o "jeitinho" é o mais atribuído às mulheres quando o tema do preconceito é abordado: é preciso ter esse "jeitinho" para poder lidar com as situações de resistência (em relação à população e aos subordinados) e segundo argumentam, é algo natural da mulher, por isso, ela conseguiria trabalhar bem como PM. Também é apontado como "jeitinho" o fato da mulher policial muitas vezes fazer dupla jornada, sendo responsável por todo cuidado da casa e dos filhos. Quando não estão alocadas no setor administrativo, que possui horário fixo de funcionamento no horário comercial, é preciso que deem o "jeitinho" para delegar o cuidado dos filhos a parentes, vizinhos e colegas, uma vez que apontam não haver auxílio direto da instituição, como creches em horários noturnos, algo que surge como demanda das policiais em trabalho ostensivo, por exemplo, que cumprem o regime de plantões, variando o horário diurno e noturno em sua atuação.

Desta forma, os trabalhos que requerem o cuidado são vistos como trabalhos de gestão de conflitos cotidianos, que seriam quase sem importância para a gestão da segurança pública, o que requereria 
conhecimentos, "jeitinhos" que as mulheres possuiriam "naturalmente". Como os policiais argumentaram a atuação cotidiana não é ensinada na escola de formação policial, mas sim, apreendida no dia a dia, no contato com a população e com o policial superior que o acompanha nas operações. Para determinadas funções, que requerem atenção e trabalho emocional, seriam mais aptas à sua realização, por já possuírem em sua composição essa disposição para o cuidado, por não ser algo que pode ser ensinado na escola de formação.

Pudemos observar que houve uma mudança legislativa, mas também no entendimento do que seria o verdadeiro trabalho de polícia na instituição. As entrevistadas e os entrevistados apontam sobre a falta de reconhecimento de seus pares para seu trabalho de prevenção, atenção a populações mais vulneráveis e atuação em projetos sociais e escolares, e argumentam sobre a valorização da população sobre seu trabalho ostensivo. Há uma mudança no entendimento do trabalho policial, principalmente no trabalho realizado pelas mulheres, voltando-se principalmente para o trabalho de combate o crime, do estar nas ruas fazendo patrulhamento em rondas.

De acordo com o trabalho de Brasil e Fachinetto (2016), e algumas falas das entrevistadas e dos entrevistados, há uma desvalorização generalizada no trabalho policial e suas condições de trabalho. Pouco ou nenhum equipamento de segurança, salários baixos, estresses, exposição constante a conflitos armados e situações de amaça a familiares. Assim como Santos, Fachinetto e Teixeira (2012), podemos destacar a importância em pensar o trabalho na segurança pública de acordo com as falas dos próprios atores da área, entendendo as políticas públicas em relação também àqueles que atuam nela. O trabalho feminino na polícia nos parece importante para auxiliar a compreender o trabalho da polícia como um todo, marcando os desafios de atuação, internos e externos. Mas também nos ajuda a entender o processo precário de trabalho que essas mulheres estão submetidas, que apesar das garantias legais de um contrato público, possui ainda muitos aspectos de desgaste durante a carreira.

Trazer o trabalho feminino no policiamento se faz importante para compreendermos a instituição como não homogênea, que possui conflitos e 
disputas internas, assim como vários outros tipos de trabalho o apresentam. Apesar de várias falas das entrevistadas e dos entrevistados buscarem destacar, mais do que as dificuldades, as superações na construção da carreira, o silenciamento das experiências negativas com o trabalho pode também significar uma positivação e busca por valorização da profissão para uma pesquisadora de fora da instituição. Colocar em pauta a discussão sobre o trabalho policial e as mudanças no entendimento do que é o fazer policial nos permite compreender que tipo de polícia é desejada, reconhecida e permitida de atuar.

\section{Referências bibliográficas}

BEAUVOIR, Simone de. O Segundo Sexo: Fatos e mitos. $4^{\text {a }}$ ed. São Paulo: Difusão Europeia do Livro, 1970.

BONELLI, Maria da Glória. Profissionalismo, gênero e significados da diferença entre juízes e juízas estaduais e federais. Contemporânea Revista de Sociologia da UFSCar. São Carlos, 2011, n. 1.

BRASIL, Glaucíria. M.; FACHINETTO, Rochele. F.. As polícias não têm rosto de mulher: invisibilidade e luta por reconhecimento. O Público e O Privado, Fortaleza, v. 28, 2016.

DENARI, Giulianna. B.. ?Um sorriso e o batom?: as narrativas sobre a história da inserção e permanência das mulheres na Polícia Militar do Estado de São Paulo. Anais V Seminário Internacional do Programa de Pós-Graduação em Sociologia da UFSCar, 2015.

DURHAM, Eunice. A caminho da cidade. $3^{\text {a }}$ ed. São Paulo: Perspectiva, 1984.

FÓRUM BRASILEIRO DE SEGURANÇA PÚBLICA; NÚCLEO DE ESTUDOS EM ORGANIZAÇÕES E PESSOAS. As mulheres nas instituições policiais. 2015. em: http:/ / www.forumseguranca.org.br/files / files / MulheresInstituicoesPolicias_ final.pdf. Acesso em: 24/09/2015.

HIRATA, Helena e KERGOAT, Daniela. Divisão sexual do trabalho profissional e doméstico: Brasil, França, Japão. In: COSTA, Albertina O. et al (orgs.) Mercado de trabalho e gênero, comparações internacionais. Rio de Janeiro: Editora FGV, 2008.

HIRATA, Helena e GUIMARÃES, Nadya A. Introdução. In: (orgs.). Cuidado e Cuidadoras: as várias faces do trabalho do care. São Paulo: Atlas, 2012. 
MINISTÉRIO DA JUSTIÇA. Mulheres nas Instituições de Segurança Pública: Estudo Técnico Nacional. Brasília - 2013.

MOLINIER, Pascale, "Ética e trabalho do care". In: HIRATA, H., GUIMARÃES, N. (Orgs.). Cuidado e cuidadoras. As várias faces do trabalho do care. São Paulo: Atlas, 2012.

MOREIRA, Rosemeri. Sobre Mulheres e Polícias: A construção do policiamento feminino em São Paulo (1955-1964). Tese de doutorado. Programa de Pós-Graduação em História. Universidade Federal de Santa Catarina, 2011.

PASINATO, Vania. Mulheres nas Instituições de Segurança Pública: Estudo Técnico Nacional. In: BRASIL. Secretaria Nacional de Segurança Pública (SENASP). Brasília, 2013.

PERTICARRARI, Daniel. Foi com o trabalho que me tornei homem: trabalho, gênero e geração. Tese de doutorado. Programa de Pós-Graduação em Ciências Sociais, Universidade Federal de São Carlos. São Paulo, 2007.

PISCITELLI, Adriana. Re-criando a categoria mulher? In: ALGRANTI, Leila Mezan. (Org.). A prática feminista e o conceito de gênero. v. 48, Campinas: IFCH/UNICAMP, 2002.

Interseccionalidades, categorias de articulação e experiências de migrantes brasileiras. Sociedade e Cultura, Goiânia, v. 11, n. 2, 2008.

SANTOS, José Vicente. T. et al. Configurações e obstáculos: as mulheres na segurança pública. Revista Brasileira de Segurança Pública, São Paulo, v. 6, n. 2, 2012.

SILVA, Cristina R. A casa e o quartel: uma análise antropológica sobre o Exército e a Família na Academia Militar das Agulhas Negras. Dissertação de mestrado. Programa de Pós-Graduação em Antropologia Social. Universidade Federal de São Carlos, 2010.

SOARES, Barbara. M.; MUSUMECI, Leonarda. Mulheres policiais: presença feminina na Polícia Militar do Rio de Janeiro. 1 ed. Rio de Janeiro: Civilização Brasileira, 2005.

Polícia e Gênero: presença feminina nas PMs brasileiras. Boletim de Segurança e Cidadania. Rio de Janeiro, n. 4, 2004.

SOUZA, Marcos S. "Sou policial, mas sou mulher": gênero e representações sociais na Polícia Militar de São. Tese de doutorado. Instituto de Filosofia e Ciências Humanas, Universidade Estadual de Campinas, 2014. 